\title{
The Correlation between Personal and Work-related Stress and the Feasibility of Managing both Successfully in Today's Society
}

\author{
Elu Akpala-Onnekikami-PhD. \\ Adjunct Professor \\ Department of Business and Economics \\ California State University \\ Los Angeles, CA
}

Received: April 6, $2020 \quad$ Accepted: Sep. 14, $2020 \quad$ Published: October 1, 2020

doi:10.5296/jmr.v12i4.17520 URL: https://doi.org/10.5296/jmr.v12i4.17520

\begin{abstract}
Personal and Work-related stress are considered an integral part of one's life in our contemporary times. Stress has been defined in several ways, but most scholars on the subject are of the opinion that stress is caused by a stimulus that can be either psychological or physical. The concept of stress can be viewed as a mental and physical condition that occurs when individuals adjust or change to cope with a threatening environment. This review of the literature on the subject focuses on the relationship between personal and work-related stress, and how it could be reduced so that employee's health will not be compromised and, if managed properly, could lead to happy and productive workers. Furthermore, this review focuses on the nature of stress, both individual and organizational causes, as well as finally strategies for dealing with stress.
\end{abstract}

Keywords: Stress, Individual causes of stress, Organizational causes of stress, controlling and managing stress 


\section{Introduction}

In contemporary times, individuals, human resources (HR) practitioners, medical professionals, and all levels of managers in organizations have placed significant focus on individual and work-related stress because of its negative effects on one's health and organizational productivity $[1,2,3]$. Individual causes of stress include, financial concerns, parenting, traffic congestion, divorce, death of a love one, and climate change to name a few. On the other hand, organizational stress includes, but is not limited to: Concerns on today's rapidly changes in technology, work load, globalization, increased competition both internally and externally in organizations, racism, sexual harassment and (lack of stability) has all led to increased stress not only in individuals employees, but also to their organizations $[4,5,6,7]$

Individual and Organizational stress has continuously increased in modern times and has created significant burden to the individuals, families, and organizations globally. Direct and indirect costs such as high turnovers, lost workdays, higher health costs are viewed as some of the general consequences $[1,8,9]$. For example, in the United States, workplace stress cost organizations about $\$ 300$ billion per annum $[1,4,8]$. It is imperative that Organizations endeavor to intervene in order to ensure, a healthy work force, eliminate inefficiencies, lower cost of health care. In addition, studies have shown that if the aforementioned are accomplished it will contribute positively to the well-being of employees and the society as a whole $[1,10,11,12,13]$

\section{Nature of Stress}

Stress has been defined in several ways, but most scholars on the subject are of the opinion that stress is caused by a stimulus $[4,5,9,14]$ that can be either by psychological or physical $[2,4,10]$. Additionally, stress could be viewed as a mental and physical condition that occurs when individuals adjust or adapt with their environment to cope. Unpleasant occurrences such as work pressures, deadlines, marital problems, financial concerns naturally could produce negative stress know as distress $[7,11]$

But there is also the concept of eustress, otherwise known as the good stress, associated with positive events such as, marriage, dating, a new job, rock climbing to mention a few. It is noteworthy that activities that provokes eustress are often very challenging, energizing, elating and rewarding $[11,15]$. Regardless, whether stress in triggered by an unpleasant or a pleasant occurrence, a review of the literature indicates that a stress reaction often begins with same autonomic nervous system (ANS) arousal that occurs when emotions tends to run high $[16,17]$.

\section{Common Causes of Stress}

Some stress is normal and, to some extent, a necessary part of our daily lives $[15,18$, 19]Despite it being something most of us experienced, what causes stress can differ from individual to individual $[9,20]$. For example, on a personal level, one person may become upset and overwhelmed by a serious traffic jam, while another individual might turn up their music and consider it a mild inconvenience. At work, an employee might perceive the way 
their boss came across to them about an issue on the job unacceptable, whereas another employee might view it as part of training $[4,14]$ This article addresses the two major causes of stresses, which are personal causes such as financial problems, personal relationships, parenting, and Organizational stressors such as task demands, physical demands, role demands, and interpersonal demands[14, 15, 21]

\section{Individual Causes of Stress}

Financial concerns according to the American Psychological Association (APA), was viewed as the top cause of stress in the United States. In 2015, an APA study reported that 72 percent of Americans stressed or were very concern about money most of the time. The majority of the participants reported money being a significant source of stress, with 77 percent feeling considerable concern about their finances $[10,22,23]$. Signs of financial concern or feeling very anxious about a monetary situation, inability to pay bills, going over one's credit limits, always arguing with loved ones about money, feeling rather guilty about spending money on non-essentials could all be negative stressful events [7, 8, 15]Stress may take time, even years to manifest itself $[15,21]$. In the long-term, the body of literature indicated that financial stress in particular could lead to high blood pressure, and cause headaches, chest pain, upset stomach, insomnia, as well as a general feeling of poor health $[11,14,17]$ Chronic stress can exacerbate other serious health problems such as, obesity and other eating disorders, increase menstrual problems, skin and hair problems to mention a few $[13,24]$.

\section{Personal Relationships}

There are individuals in our lives that might cause us stress. It could be a loved one or family member, an intimate partner, friends, or coworkers. This stress that the aforementioned individuals brings into one's life can affect one's physical and mental health $[4,19,20]$ There are other personal causes of stress such as when couples are involved in romantic relationships and could be constantly under pressure. Such relationships could be on the risk of failure and lead to stress. Other common relationship stressors include but are not limited to; being too busy to spend time with each other and share responsibilities, infrequency of intimacy, health problems, lack of communication, domestic violence and divorce [8, 11, 21, 24]

The signs of stress related to personal relationships are similar to symptoms of general stress and may include physical health and sleeping problems, depression, and anxiety as stated previously[7, 13, 16]. One may also find themselves avoiding or having conflict with the individual or becoming easily irritated by their presence. Sometimes, personal relationship stress can also be related to our relationships with people on social media platforms, such Facebook $[19,20]$. For example, social media tends to naturally encourage comparing oneself to others, which can lead to the stress of feeling inadequate. It also makes bullying easier $[1,4]$.

\section{Daily Active Life}

Day-to-day stressors are our daily inconveniences today includes things such as misplacing keys, running late, and forgetting to an important item when leaving the house. Usually, these are just minor setbacks, but if they become frequent, they could become a source of anxiety affecting our physical and/or psychological health. Currently, the stress associated with being 
too busy is becoming increasingly common $[9,19,24]$

As alluded to earlier on, in our contemporary society people are busier than ever, and that adds a lot of stress to one's life. In some situations, busyness is due to necessity, such as having to work a second job. Other times, it is due to guilt and not wanting to disappoint others. People may not say "no" and end up having little time for themselves, or overlook their own basic needs, such as eating right and exercising, due to lack of time [20, 23].

\section{Organizational Causes of Stress}

Studies have shown that work related stress affects majority of American workers[8, 9, 24]. The Centre of Disease Control and Prevention (CDCP) noted that the nature of work itself is changing in rapid pace in today's society. Most Organizations expect their employees to work long hours, especially during economically tough times, often for less pay $[7,8,10]$ The consequences of the situation often lead to fear, uncertainty and stress. Stress, as alluded to earlier on, is a consequence of physical, emotional, social, economic or other such factors that requires a response to change. Organizational stress, then refers in part to the harmful responses that occurs when the expectations of the job does not necessarily match the employee's capabilities $[8,11,15,23]$.

It is imperative that job stress not be confused with challenges, which can motivate employees to learn new skills that will propel them to higher levels of productivity [15, 22]Well-tailored challenges can be an important aspect of productive work [15]But when Challenges becomes overwhelming, it can easily lead to stress. The ability of workers to deal with job related stress can often determine their success or failure in their role for the organization. The review of the literature indicates that there are four major organizational stressors: task demands, role demands, physical demand and interpersonal demands $[8,9,11$, $15]$

\section{Task Demands}

As the name suggests, task demands are stressors associated with the task of the specific job an employee is expected to perform. Some jobs or occupations by nature tend to be more stressful than others[1, 5, 15]. For example, neurosurgeons, air traffic controllers, or any related occupations could be inherently stressful $[9,11,15]$ In addition, unhealthy job conditions that exists in some occupations, such as coal mining and toxic waste industries, could be especially stressful $[11,15]$ Employees in relatively secure jobs are not likely to worry about the feasibility of losing their jobs, compared to jobs with high turnover, for example. Finally, a major task demand stressor is work overload. Overload often takes place when an employee simply has more work than they can handle. It could be quantitative or qualitative. An overload is said to be quantitative when an employee is given too many tasks and too little time to perform. On the other hand, a qualitative overload occurs when an employee is believed to lack the ability to do the job $[5,6,24]$

\section{Physical Demands}




\section{Ml Macrothink}

Journal of Management Research

ISSN 1941-899X

2020, Vol. 12, No. 4

The physical requirements of a job can be overwhelming $[9,17,21]$ The demand is often a function of the physical characteristics of the setting of the job. For example, working outdoors in very hot temperatures or working in an improperly heated/cooled office could lead to stress. An office that is poorly design could also be problematic. It could become difficult for employee is such an environment to have any kind of privacy, or otherwise promote little or no social interaction. Employees who work nights could also feel stress due to the way their daily sleep schedules and leisure time activities might be affected $[15,17,21]$

\section{Role Demands}

A job role that is not made clear to employees could be a source of stress $[4,7,15]$ A role is the set of expectations that an organizational position is expected to perform in the course of an individual doing their job. Organizations expect an individual occupying a position to act in certain ways. These expectations tend to be transmitted both informally and formally [17, 18, 21]In some circumstances, however, "errors" might creep in, resulting in stressful situations termed role conflict, role ambiguity and role overload[14, 15]. Finally, other sets of organizational stressors include, group pressures, such as pressure to restrict output, and pressure to conform to group norms or unethical behavior. For example, the well documented pressure by Wells Fargo bank on its employees to create fraudulent accounts on their existing customers is a case in point.

Additionally, conflicting personalities and behaviors in the workplace might become a source of stress. Conflict tends to occur when two or more individuals work together when their attitudes, personalities and behaviors are different [7, 12, 14]. For example, an employee with an internal locus of control might get frustrated with an individual with external locus of control[1, 10, 19]. Similarly, an employee who prefers a peaceful and quiet environment may experience stress if a close office peer's work requires them to be talking on the phone most of the time.

Finally, it is imperative to note that in the contemporary workforce, individuals experience stress from a variety source simultaneously. For example, as previously stated, employees that are dealing with a situation such as a divorce, a sick child, or the death of a loved one will undoubtedly experience stress from the impact of such events $[6,22]$ Understandably, employees facing such issues outside of work tend to be affected while at work too.

\section{Consequences of Stress}

It is important to note that stress has numerous negative consequences, as previously alluded to. There are both individual consequences and organizational consequences[15, 21], and these consequences can be interconnected. For example, an employee who abuses drugs or consumes alcohol on the job may perform very poorly and create a hazard for other employees. This article will divulge further into the two categories of the consequences of stress.

\section{Individual Consequences}


The individual consequences of stress are those outcomes that mainly will affect the individual $[11,15,21]$. The company or organization might suffer directly or indirectly, but it is often the individuals that suffers the most. Stress tends to produce behavioral, psychological and medical consequences, as previously noted [8, 10]The behavioral consequences of stress might harm the individual under stress or others.

For example, research has shown that individuals that smoke tend to do so more when they experience stress personally or at work, which can lead to various types of cancer [8, 20]Other behavioral consequences include, drug abuse, propensity to accidents, aggression, violence and in some cases, appetite disorders (8). The psychological consequences of stress could be linked to an individual's mental health and wellbeing $[13,17]$ When individuals experience too much personal or work stress, they might become depressed. The medial consequences of stress could affect the individual psychological wellbeing. Stroke and heart diseases have also been linked to stress [7, 8, 9] Additionally, too much stress has been linked to backaches, headaches, ulcers and intestinal disorders, and even acne and hives [8, 21, 24]

\section{Organizational Consequences}

Each of the discussed individual consequences previously stated can affect the organization. Other results of stress that tend to have direct consequences include decline in job performance, negative changes in behavior and in some cases, total withdrawal. Decline in work performance is one of the consequences of stress[4, 6, 7]. Such decline is often translated into very poor quality of work and lower productivity [15]For managers it could mean faulty decision making from employees, or disruptions in working relationship with other employees, as such employees become irritable and difficult to get along with $[5,6]$

From the organizational perspective, the two most significant forms of withdrawal behavior are often absenteeism and quitting [18, 20]Individuals going through stress are more likely to call in sick or even consider leaving the company. There could be other subtle forms of withdrawal, such as an employee missing deadlines, coming late to work and taking long breaks. As previously noted, employee violence is one the consequences of stress. This could be problematic to the organization especially if the violence it is directed to other employees $[15,22,23]$

\section{Controlling and Managing Stress}

As alluded to previously, historically and more so today, stress is widespread and has the potential of being disruptive in organizations. It is important for individuals and organizations to be concerned with how to manage it effectively. Many methodologies or strategies have been developed for individuals and organizations to manage stress $[9,15,21]$

\section{Individual Coping Strategies}

There have been many proposals on individual strategies in coping with stress. One of most important suggested strategy is exercise [8, 9, 17, 19]Numerous studies have shown that individuals that exercise regularly tend to feel less stress and tension. Additionally, such individuals are more self-confident and show greater optimism about life and are less likely 
to have strokes or heart attacks than individuals that are inactive [8, 9, 24]Another individual coping strategy is relaxation. Relaxation can take many formats. One of the ways to relax is to take vacations regularly. Studies have shown that people tend to reenergize after a vacation. Relaxation could also mean taking time to do whatever the stressed individual might enjoy doing that brings them pleasure, such as listening their favorite artist and watching comedies $[8,9,10,13]$

Another recommend way of managing stress is time management. It is important to learn to prioritize in today's high pressure and hectic environment and managing one's time could help in managing stress $[3,14,22]$ A popular approach to managing time is to make a list every morning of thing that needs to be done. It is recommended that items be grouped in categories: Must-do activities, things that can be performed and trivial things that could be postponed or delegated[7, 15]. These strategies help individuals do more important things daily and encourages less important things to be delegated.

A final individual coping strategy is to maintain support groups. A support group is often a group of friends or family members who the individual often spends the most time with. For example, going out with a group of friends to a tennis or basketball game could help relieve stress $[3,11,23]$ Studies have shown that supportive friends and family can help individuals deal with normal stress on an ongoing basis.

\section{Organizational Coping Methods}

Some organizations and their employees are of the assumption that high levels of workplace stress are normal and enable them to stay productive and profitable $[9,15]$ But research tends to challenge such assumptions. Some studies have shown that stressful working conditions are linked to increased tardiness, absenteeism and can even lead employees to quit their jobs. Research also indicates that employees who takes time off because of stress average 20 days off-job-site, which as stated earlier, leads to tremendous financial costs for organizations annually $[8,10,15]$ An organization that has a healthy workplace is defined as the employer that has low rates of illness, injury and disabilities in its workforce, while remaining buoyant and competitive.

Today's organizations are increasingly realizing the need to get involved in managing their workers stress level $[4,17,24]$ There are two schools of thought on these views. One school of thought is of the opinion that in some circumstances, organizations themselves are the sources of their employees' stress and should consequently help in addressing it. The second school of thought is of the opinion that when employees experience lower stress levels, they tend to be more efficient and produces at high level $[13,14,16]$

\section{Institutional Programs}

There are several actions that can be utilized by organizations to ameliorate job stress, such as stress management and training, and Employee Assistance Programs (EAP) [11, 15, 21]EAP can help improve an employee's ability to deal with work situations by understanding the sources of stress, the effects such stress could have on their health and offering strategies in managing or eliminating those sources. One such strategy could simply be by managing their 
time better or practicing relaxation exercises as previously stated. Another way in preventing workplace stress is by hiring a consultant who can recommend new ways to improve a toxic work environment or culture [21, 23]

Other Organizational strategies in mitigating job stress includes; ensuring that employees' workload are aligned with their capabilities; designing jobs that would provide opportunities and meaning for workers to be successful. Additionally, clearly defining employees' roles and responsibilities could be of be very helpful. It is imperative also for organizations to provide professional development and for employees to be empowered to participate in decision making about their jobs. Establishing work-life balance schedules that take into consideration the demands and responsibilities outside of work could make a huge difference $[8,10,15]$

In addition, workers also have the ability in maintaining good mental health and reduce stress in their own lives as indicated earlier on[23]. There are several ways in accomplishing this, such as learning to relax and listening to their favorite music during their breaks. Furthermore, prioritizing, and managing their time well and communicating effectively with their coworkers can be very effective in dealing with both personal and organizational stress. It is important and recommended that making lifestyle changes, such as exercising more or making good and healthy food choices, can decrease stress according to some scholars [15, $17,24]$ It is important to note that job stress can never be eliminated, but strategies can be effective in ameliorating stressful occurrences and improving morale and productivity of workers in all types of organizations.

\section{Conclusion}

Stress remains a huge societal problem, both privately and organizationally. Stress is a response or reaction to stimulus. It is a psychological or physiological response shown when individuals face situations they perceive to be threatening. There are individual and organizational causes. Individual or private causes of stress, such as loss of a loved one, parenting issues could be problematic. Work related stress are caused by concerns such as physical and role demands.

This review indicates that there is a correlation between personal and work-related stress. When people are stressed, in most cases will carry it to the workplace and the other way around if they are stressed at work. Majority of the body of the literature on the subject indicates that excessive stress tends to have negative effects, such as our immune system being compromised and is some cases general burnout.

The strategies of dealing with stress are divided into mainly two categories which are individual and organizational methodologies. It is imperative that today's society, not only should individuals and employees be concerned but organizational leaders and management should also be cognizant about ways in reducing stress.

\section{References}


Amstad, F. T., Meier, L. L., Fasel, U., Elfering, A., \& Semmer, N. K. (2011). A meta-analysis of work-family conflict and various outcomes with a special emphasis on cross-domain versus matching-domain relations. Journal of Occupational Health Psychology, 16, 151-169. https://doi.org/10.1037/a0022170

American Psychological Association. (2014). Measures of organizational stressors. Retrieved from http://supp.apa.org/books/

Andreassi, J. K. (2011). What the person brings to the table: Personality, coping, and work-family conflict. Journal of Family Issues, 32,1474-1499. https://doi.org/10.1177/0192513X11401815

Baer, R. A., Carmody, J., \& Hunsinger, M. (2012). Weekly change in mindfulness and perceived stress in a mindfulness-based stress reduction program. Journal of Clinical Psychology, 68, 755-765. https://doi.org/10.1002/jclp.21865

Biron, C., \&Karanika-Murray, M. (2014). Process evaluation for organizational stress and well-being interventions: Implications for theory, method, and practice. International Journal of Stress Management, 21,85-111. https://doi.org/10.1037/a0033227

Cancelliere, C., Cassidy, J. D., Ammendolia, C., \& Côté, P. (2011). Are workplace health promotion programs effective at improving presenteeism in workers? A systematic review and best evidence synthesis of the literature. BMC Public Health, 11, 395. https://doi.org/10.1186/1471-2458-11-395

Chandra, V. (2012). Work-life balance: Eastern and western perspectives. International Journal of Human Resource Management, 23, 1040-1056. https://doi.org/10.1080/09585192.2012.651339

Centers for Disease Control and Prevention. (2012). Browse occupational safety \& health topics. Retrieved from http://www.cdc.gov/niosh/docs/99-101

DeTienne, K., Agle, B., Phillips, J., \& Ingerson, M. C. (2012). The impact of moral stress compared to other stressors on employee fatigue, job satisfaction, and turnover: An empirical investigation. Journal of Business Ethics, 110, 377-391. https://doi.org/10.1007/s10551-011-1197-y

Donald, I., Taylor, P., Johnson, S., Cooper, C., Cartwright, S., \& Robertson, S. (2005). Work environments, stress, and productivity: An examination using ASSET. International Journal of Stress Management, 12, 409-423. https://doi.org/10.1037/1072-5245.12.4.409

Grawitch, M. J., Maloney, P. W., Barber, L. K., \& Mooshegian, S. E. (2013). Examining the nomological network of satisfaction with work-life balance. Journal of Occupational Health Psychology, 18, 276-284. https://doi.org/10.1037/a0032754

Griffin, R.W \& Moorhead (2014). Organizational behavior, Managing people and organizations. Canada South-Western, Cengage Learning, 22. 
Ho, V. (2012). Interpersonal counterproductive work behaviors: Distinguishing between person-focused versus task-focused behaviors and their antecedents. Journal of Business \& Psychology, 27, 467-482. https://doi.org/10.1007/s10869-012-9256-7

Karam, C. M. (2011). Good organizational soldiers: Conflict-related stress predicts citizenship behavior. International Journal of Conflict Management, 22, 300-319. https://doi.org/10.1108/10444061111152982

Kossek, E. E., Kalliath, T., \& Kalliath, P. (2012). Achieving employee well-being in a changing work environment: An expert commentary on current scholarship. International Journal of Manpower, 33, 738-753. https://doi.org/10.1108/01437721211268294

Lerner, D., Rodday, A. M., Cohen, J. T., \& Rogers, W. H. (2013). A systematic review of the evidence concerning the economic impact of employee-focused health promotion and wellness programs. Journal of Occupational and Environmental Medicine, 55, 209-222. https://doi.org/10.1097/JOM.0b013e3182728d3c

Matheson, J. L., \& Rosen, K. H. (2012). Marriage and family therapy faculty members' balance of work and personal life. Journal of Marital and Family Therapy, 38, 394-416. https://doi.org/10.1111/j.1752-0606.2009.00137.x

McVicar, A., Munn-Giddings, C., \& Seebohm, P. (2013). Workplace stress interventions using participatory action research designs. International Journal of Workplace Health Management, 6, 18-37. https://doi.org/10.1108/17538351311312303

Rantanen, M., Mauno, S., Kinnunen, U., \& Rantanen, J. (2011). Do individual coping strategies help or harm in the work-family conflict situation? Examining coping as a moderator between work-family conflict and well-being. International Journal of Stress Management, 18,24-48. https://doi.org/10.1037/a0022007

Spurgeon, P., Mazelan, P., \& Barwell, F. (2012). The organizational stress measure: An integrated methodology for assessing job-stress and targeting organizational interventions. Health Services Management Research, 25, 7-15. https://doi.org/10.1258/hsmr.2011.011016

Tessema, M. T., Tsegai, G., Ready, K., Embaye, A., \& Windrow, B. (2014). Effect of employee background on perceived organizational justice: Managerial implications. International Review of Administrative Sciences, 80, 443-463. https://doi.org/10.1177/0020852313514516

Tetrick, L. E., \& Campbell-Quick, J. (2011). Overview of occupational health psychology: Public health in occupational settings. In J. Campbell-Quick \& L. E. Tetrick (Eds.), Handbook of occupational health psychology (2nd ed., pp. 3-20). Washington, DC: American Psychological Association. https://doi.org/10.1037/10474-001

VanWormer, J. J., Fyfe-Johnson, A. L., Boucher, J. L., Johnson, P. J., Britt, H. R., Thygeson, N. M., \& Dusek, J. A. (2011). Stress and workplace productivity loss in the heart of new Ulm project. Journal of Occupational and Environmental Medicine, 53, 1106-1109. https://doi.org/10.1097/JOM.0b013e318229ab18 
Wang, J., \& Verma, A. (2012). Explaining organizational responsiveness to work-life balance issues: The role of business strategy and high-performance work systems. Human Resource Management, 51, 407-432. https://doi.org/10.1002/hrm.21474

Zhang, R. Y., Liu, X. M., Wang, H. Z., \& Shen, L. (2011). Service climate and employee service performance: Exploring the moderating role of job stress and organizational identification. Service Industries Journal, 31, 2355-2372. https://doi.org/10.1080/02642069.2010.503873 